\title{
A implicação do pesquisador na pesquisa interacionista na escola
}

The researcher's involvement in interactionist research at school

La implicación del investigador en la investigación interaccionista en la escuela

Ruth Bernardes de Sant'Ana*

\begin{abstract}
Resumo
Toda pesquisa de campo é participante, mas com graus diferentes de participação dos sujeitos no universo pesquisado, pois, mesmo naquela baseada em contrato deliberado de não intervenção, a relação intersubjetiva pesquisador-pesquisado produz sempre alguma interferência no processo investigativo. Este artigo retoma essa discussão, sobretudo com base nas teorias de implicação pesquisador-pesquisado de Barbier e Lapassade, em diálogo com a perspectiva interacionista de Mead, Berger \& Luckmann e Goffman. Para tal, remete à análise da implicação, que consiste em interpretar como o pesquisador reage aos elementos conscientes e inconscientes, presentes no jogo interacional em que se encontra envolvido durante a sua permanência na pesquisa de campo, o que afeta, em maior ou menor grau, o processo de investigação. O tema ganhou impulso nos anos 60 do século XX, mas não se esgotou; razão pela qual está sendo problematizado aqui, com ênfase na observação do cotidiano escolar.
\end{abstract}

Palavras-chave: interacionismo simbólico; análise institucional; implicação; pesquisa em educação.

\begin{abstract}
Any field research is participative by nature, although with different levels of the subjects' participation in the investigated universe, for even in a research based on a deliberate agreement of non-intervention, the inter-subjective relationship between the researcher and those researched always gives rise to some interference in the investigation process. This paper reviews that discussion, especially regarding Barbier's and Lapassade's theories of implication between the researcher and those researched, in close dialogue with Mead's, Berger \& Luckmann's, and Goffman's interactionist perspective. For such, an analysis of the implication is made, consisting of interpreting how the researcher reacts
\end{abstract}

Doutora, professora de Psicologia Social na graduação em Psicologia, do mestrado em Psicologia e do mestrado em Educação na Universidade Federal de São João del-Rei-MG. E-mail: ruthbs@ufsj.edu.br. 
to conscious and unconscious elements present in the interactional play in which he is involved during the field research, which affects the investigation process to some extent. This theme gained momentum in the 1960s, but it is still open for discussion, which is why it is the focus of this paper, with emphasis on school daily life.

Key-words: symbolical interactionism; institutional analysis; implication; research in education.

\section{Resumen}

Toda investigación de campo es participante, pero con un grado diferente de participación de los individuos del universo investigado, incluso en aquellas basadas en un contrato deliberado de no intervención, la relación intersubjetiva investigador - investigado produce siempre alguna interferencia en el proceso de investigación. Este artículo retoma esa discusión, especialmente a partir de las teorías de implicación investigador - investigado de Barbier y Lapassade, en diálogo con la perspectiva interaccionista de Mead, Berger \& Luckmann y Goffman. Para ello, se remite al análisis de la implicación, que consiste en interpretar como el investigador reacciona ante los elementos conscientes e inconscientes presentes en el juego de interacción en el que se encuentra involucrado durante su estancia en la investigación de campo, lo que afecta, en mayor o menor grado, el proceso de investigación. El tema fue impulsado en los años 60, del siglo XX, pero no se agotó, razón por la que está siendo problematizado aquí, con énfasis en la observación de la rutina escolar.

Palabras clave: procesos psicosociales; investigación; implicación; interacción; escuela.

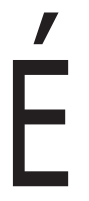

possível que alguém faça pesquisa de campo saindo ileso do jogo de intersubjetividade que a interação face a face produz? Parafraseando Machado (2002), podemos dizer que toda pesquisa de campo é participante, pois, mesmo na pesquisa de campo baseada em contrato deliberado de não intervenção, sempre existe alguma interferência do jogo relacional nascido das interaçôes pesquisador-pesquisado naquilo que é pesquisado. Esse é o mote do trabalho aqui apresentado, que retoma a discussão sobre o lugar ocupado pelo pesquisador diante do seu objeto de investigação e alguns de seus desdobramentos na produção de conhecimento, com base na junção de alguns elementos das teorizaçôes sobre a implicação do pesquisador (Barbier, 1985; Lapassade, 1989 e Lourau, 1995) e na teoria interacionista, 
principalmente de Mead (1967), Goffman (1970, 1987) e Berger e Luckmann (2002), com o objetivo de uma retomada crítica da abordagem da escola.

A discussão sobre as relações entre o pesquisador e o seu objeto de pesquisa é um tema recorrente no campo do conhecimento nomeado como científico. Hoje é amplamente aceito que nenhuma área do conhecimento pode escapar das dificuldades produzidas pela subjetividade do investigador, pois este, ao escolher o objeto de sua investigação, já traz consigo a influência do seu contexto de inserção, de seus grupos de referência, de suas preferências intelectuais do momento e de suas idiossincrasias. Destarte, o questionamento às formas de participação do pesquisador na investigação da escola, ligado ao da interferência, nos sujeitos investigados, dos dispositivos de investigação por ele definidos, constituiu um problema de pesquisa que coloca em suspeição as pretensões de total controle da subjetividade do investigador, por meio do método próprio ao paradigma positivista, nas ciências humanas.

O trabalho de Devereux (1977) é muito elucidativo a esse respeito. Ele observou que, tanto no campo das ciências naturais e exatas quanto no das ciências humanas, o pesquisador tem a percepção do seu objeto de pesquisa afetada pelos processos contratransferenciais dos participantes da produção do conhecimento ${ }^{1}$. Embora esse problema afete também as ciências exatas e naturais, a sua ressonânciaé maior nas ciências humanas, pois, como bem ressalta Barbier (1985, p. 106), "De fato as ciências humanas são mais vulneráveis à ação subterrânea da subjetividade na elaboração e desenvolvimento de uma pesquisa”. Isso acentua a importância de se compreender a implicação do pesquisador no processo de investigação nas ciências humanas, conforme ressaltam Devereux (1977), Barbier (1985) e Machado (2002).

Ao refletir sobre a pesquisa, conjugada ou não com a intervenção psicossociológica, esses autores afirmam que, em sentido amplo, a implicação remete a elementos conscientes e inconscientes que perpassam as atitudes adotadas pelo investigador diante de seu campo de investigação, dos temas escolhidos, as relações que estabelece com os sujeitos sob os quais recai seu interesse, e assim por diante. Ainda que reconheçam as escolhas conscientes feitas pelos pesquisadores, os autores acima compartilham a posição teórica de que a implicação (Barbier, 1985; Lourau, 1995) não se restringe somente às escolhas deliberadas, racionais, pois sugere também o envolvimento do investigador, por vezes inconsciente, na realização de um trabalho de campo. Portanto, a implicação vai além de uma decisão consciente de engajamento

Como essa questão tem sido tratada nas ciências naturais e exatas não são trazidas aqui. Referências teóricas sobre o referido debate podem ser encontradas em Machado (2002). 
em um empreendimento coletivo, seja ele um processo de trabalho, um tipo de pesquisa, a participação em um grupo, instituição ou comunidade.

Tal posição tem raízes em um movimento nas ciências humanas, denominado institucionalista (sobretudo na vertente conhecida como "análise institucional", de origem francesa), o qual, a partir da década de 60 do século XX, propóe que se desloque a noção de implicação da esfera da clínica psicanalítica para o mundo institucional, de modo que a análise da implicação deixa de se reduzir à mobilização (consciente ou inconsciente) provocada pelo outro no analista, pois passa a envolver registros múltiplos e heterogêneos, ligados a diferentes dimensões da experiência do sujeito, tais como o econômico, o político, o afetivo, o libidinal. Nessa perspectiva, com base em uma caracterização do suposto outro (indivíduo, grupo, organização, comunidade, etc.), presente ou idealizado, o investigador empreende o "delineamento" de pesquisa, que envolve ou não uma intervenção stricto senso. Daí nasce uma concepção de análise da implicação, voltada para a interação face a face; esta consiste em interpretar como o pesquisador reage aos elementos presentes no jogo interacional que o envolve durante a sua permanência na pesquisa de campo, afetando, em maior ou menor grau, o processo de investigação. Tanto o pesquisador quanto o objeto pesquisado são afetados por "não ditos" que os pesquisadores devem procurar decifrar.

A concepção interacionista norteadora dessa reflexão é inspirada na Psicologia social de Mead (1863-1931), uma perspectiva teórico-metodológica desenvolvida no início do século XX, na Universidade de Chicago, nomeada por Blumer (1969), em 1937, interacionismo simbólico. As análises nela referenciadas privilegiam o jogo expressivo e relacional na interação face a face, que envolve palavras, formas de falar, gestos, movimentos, expressóes emocionais, etc.

Mead (1967), ao defender que todos os sujeitos têm um self nascido da interação concomitante do si mesmo com o outro, coloca a experiência humana definidora da alteridade como sendo a convivência cotidiana com a questão das fronteiras entre eu-ele(s), nós-ele(s). São fronteiras intersubjetivas, moduladas pelas significações das experiências socioculturais apropriadas pelos sujeitos em diferentes domínios da realidade, que se atualizam na interação face a face e em um jogo de ocultamento/revelação marcado por sintomas de subjetividade que dão sinais de quem sou eu, quem somos nós e quem são eles.

Essa questão da fronteira aparece nas principais formulações teóricas acerca da identidade em Psicologia como algo constituído no ponto de encontro 
entre a igualdade e a diferenciação. $\mathrm{O}$ esvaecimento e a demarcação rígida das fronteiras entre esses polos nos são apresentados, pelos processos de fusão e de negação do outro, com o anseio de uma desejada igualdade, no primeiro caso, e a sua recusa, no segundo caso.

Nessa perspectiva, o outro referencia a ação do sujeito, em seu movimento de apropriação e de rejeição às atitudes de diferentes outros que foram significativos na sua trajetória biográfica. Em meio a esse processo de formação ocorre a interiorização de um outro que poderia ser simbolizado como a condensação de um feixe organizado de atitudes que a sociedade, por meio das significações das experiências sociais mais significativas, forjadas no interior da família e fora dela, busca introduzir no indivíduo ao longo do seu processo de formação.

O outro é incorporado como mecanismo psíquico necessário à organização dos fragmentos de experiências vividas pela criança. Caso o processo seja bemsucedido, a criança se torna capaz de colocar-se no lugar de diferentes outros, o que a capacita a refletir sobre o si mesmo e os outros ao mesmo tempo. Desse modo,

O principal mecanismo de formação nasce em um processo em que o indivíduo adota a atitude e o papel do outro, experimentando ocupar esse outro lugar, revelador de si mesmo e do outro. Ao entrar no ponto de vista do outro, o indivíduo conhece uma possibilidade de compreensão de si mesmo, a expectativa do outro em relação a si, o que o conclama a uma resposta compartilhada, mesmo que minimamente (Sant'Ana, 2004, p. 25).

$\mathrm{Na}$ visão do interacionismo, as significações atribuídas às experiências pelos sujeitos na interação entre parceiros constituem a base para a análise do cotidiano institucional, uma perspectiva fecunda para a compreensão da escola, o que aproxima essa abordagem da etnografia na investigação educativa (Woods, 1989; André, 1995; Sant'Ana, 2003) e da etnometodologia da escola (Coulon, 1995), a favorecer um diálogo promissor que vai ao encontro dos estudos do cotidiano (Berger e Luckmann, 2002; Goffman, 1970; Lefebvre, 1961) e do cotidiano escolar (Sirota, 1994; Perrenoud, 1995, 1996; Sacristán, 2000).

Localizando a unidade de análise na interação, o interacionismo reconhece que o comportamento observado envolve mais do que as intençõose significações nascidas na interação, pois se trata de um processo dialético de confrontação permeado por significações que transcendem os limites da imediaticidade face a face. Na verdade, baseados em Mead (1934/1967), defendemos 
que o encontro com o outro, nas instituiçôes sociais, é sempre demarcado pelas expectativas de ação oferecidas pelas pautas de condutas instituídas pela sociedade. Assim sendo, por meio das significações compartilhadas socialmente, cada instituição forja esquema e expectativas de comportamentos mútuos entre os sujeitos, que, apesar disso, dependem do fluxo da interação e das definições das situações por eles dadas ao vivido no desenrolar do cotidiano institucional. Em uma abordagem interacionista, capturar o fluxo das significações que acompanha a interação social implica em entender as definições de situações com antecipações bem-sucedidas e aquelas em que as antecipações falham. Tais significações não são facilmente identificadas, $o$ que requer do pesquisador uma escuta atenta e implicada. Woods (1989), ao tratar do método etnográfico, assume uma posição semelhante, na medida em que defende que é possível encontrar as significações da realidade social construída pelos sujeitos, mesmo que no interior de um fluxo dinâmico e não linear de acontecimentos, em que camadas de significações de várias espessuras fazem diferentes aparições no desenrolar das interações, devendo o investigador ter um olhar atento para que sua própria percepção não se prenda em uma das camadas superficiais que participam da configuração de um fenômeno institucional. $\mathrm{O}$ autor enfatizou que

A vida em grupo pode ter certas propriedades constantes - que, por suposto - é importante descobrir - mas também é um fluxo, um processo com oscilaçôes, ambiguidades e incongruências. Nossa tendência instintiva é a de tratar de resolver essas ambiguidades e essas incongruências quando cruzamos com elas, mas essas são, na verdade, as matérias mesmas da vida, que melhor há que se compreender do que resolver e, por fim, eliminar (p. 19).

Caberia ao etnógrafo, conforme Woods, a habilidade de "escuta aguçada, a sensibilidade emocional, de penetração através das diferentes camadas da realidade, a capacidade de colocar-se na pele de seus personagens, sem perda alguma da capacidade de valorizá-los objetivamente" (1989, p. 21). Esse jogo relacional requer o desenvolvimento da capacidade de assumir o lugar do outro, teorizada por Mead, e compreender as significações atribuídas por ele à situação, em diferentes graus (Sant'Ana, 2002).

A perspectiva interacionista oferece-nos uma abordagem psicossocial suscetível de tratar tanto o lugar ocupado pelo observador na interação quanto à sua implicação no processo de investigação, pois tanto a situação de observação quanto a de entrevista são interações sociais moduladas pelos lugares de onde falam o pesquisador e o pesquisado como sujeitos sóciohistóricos, de modo que tende a ocorrer um posicionamento de cada um 
dos sujeitos em relação às expectativas identificadas nos outros acerca de suas ações, conforme a definição da situação no contexto em que se encontram envolvidos. Nesse vaivém relacional, nem sempre há uma comunhão entre perspectivas, não havendo obrigatoriamente uma simetria entre aquilo que um sujeito expressa e as significaçóes dadas ao ato expressivo do primeiro pelo outro e vice-versa. Dessa forma, a situação de pesquisa envolve um conjunto de sintomas de subjetividade expressos pelos parceiros que participam da dinâmica relacional, em que comparece o domínio do não dito, escondido ou subentendido.

Portanto, a abordagem interacionista não é, obviamente, uma simples modalidade de etnografia concebida desde a ideia de procedimentos de investigação a envolver métodos práticos de imersão de campo, entrevista, análise de discurso e de interação, etc. Ela se constrói tendo como ponto de partida o posicionamento dialógico do observador em relação ao outro (indivíduos, grupos e instituições), e as condiçôes concretas em que os sujeitos interatuam, o que remete aos feixes de significações que referenciam as ações dos sujeitos em interação.

Lapassade (1989) e Machado (2002) são autores que buscam o encontro das teorias da implicação com uma abordagem interacionista de orientação etnográfica. Com base em suas contribuições, podemos pensar que a compreensão das atitudes dos parceiros envolvidos na interação requer a interpretação de elementos que extrapolam os elementos visíveis em determinadas situações, pois a gramática da comunicação humana não se reduz ao conteúdo claramente instituído pela cultura, havendo movimentos instituintes no seu interior. Por isso os processos externos à interação devem comparecer na análise e interpretação da experiência dos atores. A palavra, o gesto, as formas de falar condensam, entre outras coisas, relaçóes sociais permeadas por relações de poder forjadas no mundo sociocultural em que os sujeitos, grupos e organizações se encontram inseridos (Sant'Ana, 2004). Machado (2002) lembra-nos de que o lugar do qual fala cada um dos sujeitos em interação já tem alguma definição prévia, com a qual essa interação também vai se defrontar. Desse modo, falar da implicação e analisá-la consistem em buscar na manifestação de cada objeto a configuração própria que este assume naquele contexto social e no interior de um determinado universo de discurso. Isso significa, também, considerar a existência da ambiguidade entre o dito e o não dito. Tais "não ditos" dos indivíduos, grupos, instituiçôes e comunidades não ficam presos necessariamente ao ideológico, à repressão ou ao recalque, ou ao subentendido da cultura, pois envolve um interjogo complexo a exigir a articulação teórico-metodológica entre os fenômenos 
micro e macrossociais, com ênfase em como ocorre a apropriação subjetiva desses fenômenos pelos sujeitos em cada situação dada. Os autores recusam a ideia de relacionar elementos separados, colocando entre eles uma ligação causal absoluta, devendo voltar-se a atenção para o vínculo entre a lógica institucional e a dos sujeitos e pesquisadores que se relacionam no campo de pesquisa.

Esses teóricos compartilham o ponto de vista de que a escolha das principais formas de participação do pesquisador no interior da pesquisa já abrange níveis diferenciados de possibilidades de envolvimento, que são modulados pelas implicaçôes próprias à subjetividade daquele nesse momento de sua biografia. Por sua vez, as formas de participação e as implicaçôes subjetivas do pesquisador tensionam o trabalho de investigação, mas a elucidação desses elementos facilita novas compreensóes da realidade. Tal processo de construção de conhecimento organiza e assegura um olhar mais complexo sobre os fenômenos estudados, pois concebe o pesquisador como um sujeito inscrito no mundo sociocultural e na sua história biográfica particular, que vive uma experiência de alteridade não facilmente inteligível, pois esta escapa a uma percepção sensível pura. Ele lida com os sintomas de subjetividade do outro que entram maciçamente na interação face a face (Berger \& Luckmann, 2002), mas é preciso decifrá-los com base nos referenciais socioculturais disponíveis.

\section{Participação e implicação na pesquisa de campo}

Conforme Mead (1967), o desenvolvimento do self torna a pessoa capaz de incorporar as múltiplas perspectivas dos atores presentes em determinadas experiências interacionais, para construir a sua própria. Ou seja, a pessoa precisa descentrar-se de si mesma para compreender as intenções subjetivas que orientam a ação dos outros, o que exige retirar do fluxo de interações sociais os elementos que lhes dão inteligibilidade.

O desdobramento desse tipo de reflexão para o plano da pesquisa indica-nos que a inovação na pesquisa interacionista requer do pesquisador a capacidade de ir ao encontro de um conjunto condensado de experiências humanas que já foram, de alguma forma, elucidadas. Ele deve aceitar como desafios a sua retomada para ampliação do processo de elucidação, quer fortalecendo as perspectivas já produzidas sobre o objeto, quer construindo uma nova posição, oferecendo-lhe uma síntese nova por uma concatenação original dos elementos ali identificados, a condensar um feixe de significações sociais.

Desse modo, a condição necessária ao desenvolvimento da pesquisa de 
campo em educação impõe à investigação uma síntese, própria das situações sociais proporcionadas pela vida na escola, bem como dos caminhos forjados pelos sujeitos nas diferentes situações de interação, a compor assim um mosaico original.

A entrada do pesquisador em vários contextos sociais, de maneira direta ou indireta (pela leitura, pelas conversas, por exemplo), permite o ingresso em um número expressivo de padrões de interação forjados pelos seres humanos e o encontro dos códigos sociais a eles subjacentes, o que pode enriquecer a sua capacidade de compreensão da realidade.

É necessário que ele se distancie de si mesmo, entre no lugar de vários outros simultaneamente e os trate como objetos epistemológicos, até que possa viver o embate entre diferentes perspectivas. Mas isso só é possível no contato com a sua carga experiencial que mobiliza um self que não é todo consciente, pois inclui o já internalizado na sua trajetória biográfica, e apresenta-se o tempo todo, em maior ou menor grau, intermediando o acesso do sujeito ao real.

Processos emocionais, afetivos, ideológicos recheiam as interaçóes sociais como coparticipantes muitas vezes não autorizados pelo pesquisador, mas como partícipes que ele não necessariamente controla, pois dizem respeito a uma implicação já existente ou nascida na relação de alteridade. Na pesquisa de campo, o pesquisador deve separar o que é dele e o que é do outro, mas esses dois elementos precisam entrar em relação, para que o conhecimento de fato se instaure, pois o próprio ato reflexivo requer tornar a perspectiva do outro e a de si mesmo como objetos para refletir "objetivamente" sobre a situação em curso ou já dada. Mas não há como separar esses elementos subjacentes à interação social do pesquisador com o seu objeto de estudo, pois eles imprimem marca na subjetividade humana, ao mesmo tempo em que compartilham dos motivos para a ação. Por isso, torna-se necessário, em maior ou menor grau, introduzir na discussão uma teorização sobre a implicação para tematizar o encontro entre essas duas dimensões da realidade, uma localizada mais facilmente na visibilidade da interação, outra a exigir a compreensão de um ausente que diz respeito à dimensão do não dito, do não confessado.

$\mathrm{Na}$ busca de uma definiçãao de implicação que não se resuma à contratransferência psicanalítica e que favoreça a ampliação do entendimento sobre o assunto, encontramos a definição de Barbier (1985) sobre a implicação, no campo das ciências humanas, como

O engajamento pessoal e coletivo do pesquisador em e por sua práxis científica, em função de sua história familiar e libidinal, 
de suas posições passada e atual nas relações de produção e de classe, e de seu projeto sociopolítico em ato, de tal modo que o investimento que resulte inevitavelmente de tudo isso seja parte integrante e dinâmica de toda atividade de conhecimento (Barbier, 1985, p. 120).

Baseados nessa posição de Barbier, podemos refletir como as diferentes pertenças socioculturais, conjugadas com as particularidades da biografia do pesquisador, participam do processo de produção do conhecimento. O sujeito é movido sempre por um projeto "sociopolítico" modulado pela inscrição de sua subjetividade naquele momento de sua história biográfica no seu mundo sociocultural. Refletindo a experiência de animador de grupo e de concretização de pesquisa-ação voltada para um projeto de transformação das relações sociais com vistas ao bem-estar coletivo em uma sociedade sem classes, em um momento histórico em que diferentes forças políticas se mobilizavam por uma nova ordem social, igualitária e emancipatória, Barbier (1985) desenvolve uma tipologia de análise de implicação que mescla elementos analíticos da psicanálise e do marxismo, buscando dar conta da relação dialética pesquisador e seu objeto de investigação, de modo a esclarecer as mediaçóes psicossociais que perpassam os seus projetos, as suas práticas e os seus produtos sociais. Ao refletir a análise da implicação na pesquisa-ação, o autor recorta três níveis em que ela ocorre, porém articulados entre si: a implicação psicoafetiva, baseada em um processo de elucidação de base psicanalítica; a histórico-existencial, relacionada ao engajamento do sujeito ao seu projeto existencial e ao projeto do grupo com o qual interage e para o qual concorrem o ethos e o habitus de classe do pesquisador, o que envolve "constelações de hábitos adquiridos, de esquemas de pensamento e de percepção sistemáticos", ligados a sua socialização na classe social de origem, a sua práxis e o seu projeto, ou seja, o projeto de transformar ou não a estrutura social por sua práxis; a estrutural-profissional, o que remete à referência ao lugar do trabalho social do pesquisador e a sua posição socioeconômica na sociedade contemporânea.

A perspectiva de Barbier exige a reflexão crítica sobre a prática social do pesquisador, de modo a não esconder as suas opções pessoais, políticas e econômicas, uma posição de recusa da concepção de investigador neutro e isento, detentor da verdade científica.

Lapassade (1991) identifica, na pesquisa de campo, uma tensão dinâmica entre participação e distanciamento, quando o principal instrumento do trabalho de campo reside na capacidade de o pesquisador entrar em relação com o objeto, abrir-se à sua escuta, mediar o diálogo entre o que disse o 
objeto e a teoria, por meio de um distanciamento crítico. Para o autor, são as interaçóes entre os sujeitos e a realidade social as produtoras do sentido, o que significa uma forte articulação entre a produção de conhecimento e a intersubjetividade. Por isso, o autor identifica o grau de implicação do investigador como o norteador dos níveis de participação do pesquisador no campo de investigação, a produzir as três formas dominantes de participação no grupo investigado, identificados por Adler e Adler (1991), como compondo as modalidades de observação participante: periférica; ativa e completa. A observação participante periférica (peripheral membership) é usada nos casos em que os observadores consideram necessário certo grau de implicação na compreensão das atividades das pessoas e de suas visões de mundo, mas, ao mesmo tempo, procuram guardar um grande distanciamento do centro. $\mathrm{Ou}$ seja, o espaço central da cena deve ser ocupado pelos sujeitos pesquisados, cabendo ao pesquisador evitar tornar-se um ator principal no campo em que se insere; isso significa buscar minimizar a possibilidade de que sua presença participe na "definição" das situações mais significativas engendradas na interação entre os sujeitos, no campo investigado.

A observação participante ativa (active membership) é escolhida por investigadores que consideram importante adquirir um estatuto no seio do grupo ou da instituição em estudo e desempenhar um papel nesse grupo, mas mantendo sempre certa distância, ou seja, procurar garantir "um pé aqui, outro lá". A conquista desse estatuto franqueia ao pesquisador a participação ativa em atividades do grupo, como se fosse um de seus membros.

Finalmente, a observação participante completa (complete membership) que se subdivide nas subcategorias oportunidade e conversão. Oportunidade, segundo Lapassade, é quando o pesquisador aproveita a chance decorrente de um estatuto por ele conquistado, o que lhe concede um lugar como membro do grupo ou instituição que lhe permite um enorme engajamento no trabalho ali desenvolvido, acompanhado de um distanciamento crítico na sua ânsia de controlar o processo de implicação. Por conversão, entende-se uma participação completa, movida por uma implicação máxima, em que o pesquisador é convertido ao "grupo dos outros". A “conversão" consistiria em um processo de transformação no mundo do investigador e engloba uma mudança de valores, crenças, comportamento e na forma de interpretar os acontecimentos, em conformidade com os ideais do grupo pesquisado. Acaba por ocorrer uma entrada maciça do pesquisador no universo dos sujeitos pesquisados e seu engajamento irrestrito em um empreendimento coletivo, a ponto de ser convertido (ideologicamente, afetivamente) para o mundo que ele se propôs a conhecer. 
Lapassade considera que a escolha do tipo de implicação "periférica" tem a sua origem numa escolha de ordem epistemológica, fundamentada no receio de que uma implicação demasiada redunde em bloqueio da possibilidade de análise. Isso nos indica que, em Lapassade, permanece a concepção de que o pesquisador pode escolher entre participar e não participar, enquanto para Devereux (1977) e Machado (2002), aquele é visto sempre como participante, em maior ou menor grau, do processo de construção do conhecimento que requer trabalho de campo.

Lapassade fala da implicação a partir da entrada no campo, após o pesquisador ter decidido se implicar pela participação, mesmo que de maneira periférica. Porém, quando falamos da implicação, consideramos que esta sempre existe, mesmo que o delineamento da pesquisa não envolva a interação face a face com os sujeitos da investigação, pois a prática de pesquisa suscita representaçôes, ideologias, valores, emoçōes que favorecem a valorização ou não de certas temáticas e percursos teóricos e metodológicos do pesquisador.

No caso das pesquisas que exigem a interação face a face com o sujeito pesquisado (observações, entrevistas diretivas ou não diretivas, e assim por diante), a escolha da forma de relação no interior da pesquisa é, entre outras coisas, modulada pela subjetividade de cada pesquisador, pois toda situação de pesquisa é recoberta pela intersubjetividade que se revela quando "cada interlocutor se localiza em relação ao outro; nenhum dos dois escapa a tal localização, nem a controla inteiramente" (Machado, 2002, p. 50). Portanto, conforme a autora, todo pesquisador deve buscar conhecer a sua posição frente ao ato de interpretação, com vistas a diminuir as possibilidades de distorção de sua tarefa específica no interior da dinâmica interativa.

O que deve ficar claro é que Lapassade põe em relevo a dimensão da implicação, no sentido de engajamento, como modulando a escolha teóricometodológica, ou seja, a investigação como processo relacional aparece como o elemento fundamental que dá vida ao processo de pesquisa. Caso o enfoque incidisse nas escolhas teórico-metodológicas mais propriamente ditas, deveríamos designar uma observação participante completa, aquela cujos investigados partilham de todo o processo de investigação, da formulação do projeto, de sua realização concreta e da tomada de decisão e avaliação envolvidas em cada etapa desenvolvida. Isso significaria compartilhar com o pesquisado inclusive o papel de pesquisador.

Embora a contribuição desse trabalho de Lapassade (1991) se volte mais para as implicações de caráter deliberado, intencional, na definição do nível de intervenção no campo pesquisado, ao falar de uma forma de participação 
completa em que se entra por um processo de "conversão", acaba por esbarrar em processos psicológicos que estão longe de ser completamente conscientes. A conversão implica em uma transformação radical da realidade subjetiva do sujeito, pois não se faz sem uma forte ligação emocional dele em relação ao grupo ao qual está se convertendo. Necessariamente entra em jogo um processo de ressocialização no seio do grupo pesquisado, pois a dinâmica afetiva em seu interior repete a dependência emocional do iniciante em relação aos "outros significativos" que marcaram o processo de socialização primário infantil (Berger \& Luckmann, 2002). A perspectiva de Barbier (1985) nos permite refletir que essa implicação máxima ocorrida nos processos de conversão poderia significar uma fusão entre o sujeito (o pesquisador) e o objeto do conhecimento (o grupo, a organização, a instituição, etc.), algo típico dos processos de conversão religiosa. Trata-se de uma experiência humana em que a dimensão da paixão, da fé, vem sinalizar a presença de elementos não conscientes que açambarcam a experiência da pessoa que vive a aventura da conversão. Apesar disso, reflete Lapassade (1991) que a existência de uma tensão entre participação e distanciamento, no conjunto dos trabalhos contemporâneos sobre observação participante, deveria ser resolvida pela passagem do pesquisador de uma posição de observador periférico a uma posição de participação completa, de maior implicação.

Ainda que Lapassade (1991) identifique como arriscada a escolha da modalidade observação participante ativa ou completa para a investigação de certos grupos (grupos de delinquentes, por exemplo), considera que, excluídos esses casos-limite, o risco maior é a recusa da não implicação. A teorização do autor permite-nos refletir que a busca de fugir do problema da implicação, através da abordagem positivista, não oferece nenhuma salvaguarda contra a subjetividade do pesquisador, pois tal abordagem impede a escuta do dado dissonante, daquele não definido previamente pela grade de observação ou pelo questionário portado pelo pesquisador.

Com base em Barbier e Lapassade, podemos refletir que não há uma forma necessariamente definida e linear de articulação entre a implicação e a participação. Quando observamos os tipos de implicação propostos por Barbier, psicoafetiva, histórico-existencial e estrutural-profissional, e procuramos relacioná-las com as modalidades de participação de Lapassade periférica; ativa e completa - deparamos um grande número de possibilidades de conexões entre elas, suscetíveis de uma multiplicidade de interpretações. $\mathrm{O}$ caso mais emblemático é aquele suposto como ocorrendo uma "fusão" entre o sujeito e o objeto do conhecimento (mais fácil de acontecer na modalidade de participação completa de Lapassade). Os desdobramentos da "fusão" podem 
ser vários, extrapolando os limites do recorte deste artigo, o que não nos impede de lembrar que isso pode ocorrer nas investigaçôes da infância e da educação, pois estas sempre remetem a uma relação com o saber e com a autoridade, o que faz dela uma relação de implicação por excelência.

A retomada de tais autores coloca-nos diante de algumas questôes para as quais devemos esboçar algumas respostas, mesmo que não definitivas. Lapassade questiona uma forma de manejo da tensão entre participação e distanciamento que ocorre em estabelecimentos de educação, quando o pesquisador evita provocar ou fazer parte das mudanças na escola, apesar de fazer a modalidade de pesquisa participante ativa. Indaga o autor sobre os dilemas que nascem dessa postura, ao dizer que

Um problema se coloca quanto à observação participante ativa, em particular nos estabelecimentos de educação: como praticar uma etnografia verdadeiramente participante ativa, evitando participar de mudanças, ou mesmo de provocá-las, o que seria então uma forma de pesquisa-ação, de intervenção de tipo psicossociológico, e não mais de observação participante stricto sensu? O observador participante ativo não corre o risco de introduzir outros valores na situação em que ele estuda? Em uma escola ou em um liceu, por exemplo, ele poderá apresentar um modo de ação permissivo, um modelo pedagógico alternativo, o que é uma forma de intervenção suscetível de mudar a situação observada. Faz-se necessário, então, definir a participação ativa como uma intervenção que não diz o seu nome? (Lapassade, 1989, p. 30).

Lapassade defende que o pesquisador leve até às últimas consequências a sua participação no processo de investigação, remetendo à necessidade de uma intervenção psicossociológica de modo que os sujeitos, pesquisados e pesquisador, assumam um papel ativo e crítico de transformação das organizações sociais em que se inserem. Trata-se de uma perspectiva progressista que manifesta a busca da transformação da ordem institucional vigente, aspira a novos modelos e projetos de vida social, como essencial para a transformação e instituição de relações sociais, necessárias à emancipação humana.

A primeira questão que buscamos responder é: deve o pesquisador desenvolver uma "intervenção completa" nas escolas, em consonância com a posição de Lapassade? Compreendemos que cabe ao pesquisador e à equipe de pesquisa responder a isso, em função das condições objetivas e subjetivas identificadas no transcurso de seu trabalho e da equipe em que atua. Lutar pela mudança institucional pela via da intervenção direta de um pesquisador ou um grupo de pesquisadores depende de uma avaliação das possibilidades 
objetivas do desenvolvimento de um projeto baseado no slogan "mudar para conhecer". Por outro lado, mesmo que o grupo compreenda as condições objetivas como favoráveis, pode não apresentar as condições subjetivas correspondentes a um projeto ambicioso de transformação de estabelecimentos de ensino e, quiçá, da instituição escola. Em determinados momentos, um grupo de pesquisa pode estar fortemente empenhado em garantir as condiçôes mínimas para o seu funcionamento, mas talvez lhe falte ânimo necessário para empreendimentos desse porte.

Trazer para a análise todas as implicações, conscientes e inconscientes, do pesquisador com o seu objeto de pesquisa é algo impossível de ser feito, pois se trata de uma tarefa muito complexa, de difícil execução prática. A busca de revelar aspectos de todas as dimensões inconscientes presentes no cenário grupal pode levar à escolha de uma perspectiva de análise da implicação de inspiração marxista e psicanalítica, que empreende a análise de conteúdos ideológicos, reprimidos, recalcados, e assim por diante, como se fosse possível dar conta da totalidade de conteúdo não consciente subjacente à interação social entre os sujeitos. Em meio ao feixe de elementos identificados pela reflexão crítica do processo grupal, ainda pode permanecer a interrogação acerca de que aspectos devem ser interpretados e quais devem ser deixados do lado de fora da análise? Identificar os conteúdos mais significativos na compreensão do processo grupal depende também da perspectiva de análise adotada pela equipe de pesquisa, o que implica em escolhas seletivas. Uma vez feita tal escolha, cabe ao pesquisador explicitar abertamente sua implicação para que a comunidade científica certifique a sua interpretação e imprima a chancela de objetividade ao seu trabalho de investigação?

\section{Considerações finais}

Aqui apresentamos uma retomada da pesquisa interacionista a partir da preocupação com a implicação do pesquisador. Buscamos mostrar a importância do interacionismo social para a compreensão da escola e de como a análise de implicação pode ser integrada à percepção do lugar do pesquisador na investigação qualitativa. Defendemos que prática de pesquisa suscita representações, valores, emoções que favoreçam a valorização de certas temáticas e percursos teóricos e metodológicos do pesquisador, em detrimento de outras. Trata-se de uma discussão que procura sensibilizar os pesquisadores para que procurem identificar os elementos conscientes e inconscientes que orientam seus comportamentos durante todo o processo 
de investigação, com vistas à compreensão dos atravessamentos que sua subjetividade pode produzir no objeto investigado.

O grande desafio colocado por essa perspectiva decorre da consideração de que a análise da implicação requer um trabalho coletivo, pois seria uma tarefa muito difícil ao pesquisador elucidar todas as suas implicações por meio de um trabalho solitário de reflexão. O modelo idealizado por todos que trabalham nessa perspectiva requer a existência de um grupo de analistas capaz de olhar do exterior a ação do pesquisador em campo e interpretar, com ele, aquilo que o mobiliza afetivamente. Desse modo, ao compreender as perturbações que o outro (a instituição, o grupo, os indivíduos) lhe provoca, poderia manejar mais adequadamente a sua posição diante do objeto investigado, o que garantiria maior objetividade científica. Constituir esse grupo de analistas é a grande dificuldade, pois as condições de trabalho dos pesquisadores não constituem facilmente tais canais de conversa, que deveriam ser constantes, processuais. Isso não significa a impossibilidade de sua concretização, mas, sobretudo, a dificuldade de sua realização plena.

De qualquer modo, sabemos que a questão da relação entre participação e distanciamento se revela o tempo todo na análise da implicação, razão pela qual os porquês da busca de aproximação ou distanciamento não podem ser vistos exclusivamente como uma escolha ligada a questôes de validade científica. Todos esses elementos intervenientes agem independentemente da validade que podem ter essas interpretações quando se adota uma perspectiva científica.

O que este artigo procurou enfatizar é que os motivos que nos conduzem ao trabalho de investigação mesclam aspectos conscientes e inconscientes. Embora os temas que mobilizam nossos interesses de pesquisa possam originar-se das questóes colocadas historicamente, nos nossos contextos sociais de inserção, não nos engajamos apenas pelo saber, pelos motivos que estão no campo consciente, mas, também, por desejos, nascidos de forças não claramente conscientes, mas que têm a ver com o prazer, com o sofrimento, com a força de criar o novo.

\section{Referências}

Adair, P. \& Adler P. (1991). Membership roles in field Research. New York: Sage Publications, Columbia University Press. 
André, Marli Eliza D. A. (1995). Etnografia da prática escolar. Campinas: Papirus.

Barbier, R. (1985). Pesquisa-ação na instituição educativa. (Tradução de Estela dos Santos Abreu e Maria Wanda Maul de Andrade). Rio de Janeiro: Jorge Zahar. (Original publicado em 1977).

Berger, P. \& Luckmann, T. (2002). A construção social da realidade. (Tradução de Floriano Souza Fernandes). Petrópolis: Vozes. (Original publicado em 1966).

Blumer, H. (1969). Symbolic interactionism: perspective and method. Englewood Cliffs: Prentience-Hall.

Coulon, A. (1995). Etnometodologia e educação. Petrópolis: Vozes.

Devereux, G. (1977).Dela ansiedadalmétodo en las ciencias del comportamiento. (Tradução de Felix Blanco). México: Siglo Veintiuno. (Original publicado em 1967).

Goffman, E. (1987). Façons de parler. (Tradução de Forms of Talk, 1981). Paris: Minuit.

Goffman, E. (1970). Estrategic interaction. Philadelphia: University of Pennsylvania Press.

Lapassade, G. (1989). L'ethnosociologie. [on-line]. Paris: Méridiens Klincksieck. Disponível em: http://193.54.168.65/docs/IMG/pdf/L_ethnosociologie2008-2. pdf. (Acesso em: 16 jul. 2009).

Lefebvre, H. (1961). Critique de la vie quotidienne: fondements d'une sociologie de la quotidienneté (v. 2). Paris: L'Arche Editeur.

Lourau, R. (1995). A análise institucional. Petrópolis: Vozes.

Machado, M. N. da M. (2002). Entrevista de pesquisa: a interação pesquisadorentrevistado. Belo Horizonte: c/Arte.

Mead, G. H. (1967). Mind, self and society. Chicago: The University of Chicago Press. (Original publicado em 1934).

Perrenoud, P. (1995). Ofício do aluno e sentido do trabalho escolar. Porto: Porto Editora.

Perrenoud. P. (1996). La pédagogie à l'école des différences. Paris: ESF Éditeur. 
Sacristán, J. G. (2000). O currículo: uma reflexão sobre a prática. Porto Alegre: Artmed.

Sant'Ana, R. B. de (2002). Experiências formativas em pré-escola: sob a perspectiva da Psicologia social de G. H. Mead. Tese de doutorado, Pontifícia Universidade Católica de São Paulo, São Paulo.

Sant'Ana, R. B. (2004). O processo de formação do sujeito e o self na Psicologia social de Mead. Psicologia Política, 4 (7), 17-44.

Sant'Ana, R. B. (2003). A pesquisa interacionista e a investigação da escola. Revista Vertentes, São João del-Rei, 22, 7-18.

Sirota, R. (1994). A escola primária no cotidiano. Porto Alegre: Artes Médicas.

Woods, P. (1989). La escuela por dentro. La etnografia en la investigación educativa. Buenos Aires: Paidos. 